\title{
Removal of Polysialic Acid-Neural Cell Adhesion Molecule Induces Aberrant Mossy Fiber Innervation and Ectopic Synaptogenesis in the Hippocampus
}

\author{
Tatsunori Seki ${ }^{1}$ and Urs Rutishauser ${ }^{2}$ \\ Departments of ${ }^{1}$ Neurosciences and ${ }^{2}$ Genetics, Case Western Reserve University, Cleveland, Ohio 44106
}

\begin{abstract}
The mossy fiber axons of both the developing and adult dentate gyrus express the highly polysialylated form of neural cell adhesion molecule (NCAM) as they innervate the proximal apical dendrites of pyramidal cells in the CA3 region of the hippocampus. The present study used polysialic acid (PSA)-deficient and NCAM mutant mice to evaluate the role of PSA in mossy fiber development. The results indicate that removal of PSA by either specific enzymatic degradation or mutation of the NCAM-180 isoform that carries PSA in the brain causes an aberrant and persistent innervation of the pyramidal cell layer by mossy fibers, including excessive collateral sprouting and/or defasciculation of these processes, as well as formation of ectopic mossy fiber synaptic boutons. These results are considered in
\end{abstract}

terms of two possible effects of PSA removal: an increase in the number of mossy fibers that can grow into the pyramidal cell layer and an inhibition of process retraction by formation of stable junctions including synapses. As these defects on granule cells in the adult animal and PSA-positive granule cells continue to be produced in the mature brain, the present findings may be relevant to previous studies suggesting that PSA-NCAM function is required for long-term potentiation, long-term depression, and learning behaviors associated with hippocampus.

Key words: hippocampal development; polysialic acid; neural cell adhesion molecule; mossy fiber innervation; mossy fiber synaptogenesis; dentate gyrus
The polysialic acid (PSA) moiety of neural cell adhesion molecule (NCAM) can serve as a negative regulator of cell interactions and is known to be associated with a variety of developmental processes that require plasticity in these interactions, including cell migration and the guidance and targeting of axons (for review, see Rutishauser and Landmesser, 1996). Moreover, PSA expression persists in certain regions of the adult brain known to exhibit physiological plasticity or self-renewal, including the olfactory bulb, suprachiasmatic nucleus, hippocampus, hypothalamus, and certain nuclei of the spinal cord (Theodosis et al., 1991; Bofanti et al., 1992; Seki and Arai, 1993a). In the hippocampus, PSA expression by newly generated granule cells and their axons occurs both during development and in the adult (Seki and Arai, 1993b, 1995). In addition to these expression patterns, the loss of PSA-NCAM in NCAM-deficient mice or wild-type mice treated with the PSA-specific endoneuraminidase (endo $\mathrm{N}$ ) has been associated with alterations in a variety of brain functions, including learning and memory behaviors (Cremer et al., 1994; Becker et al., 1996), maintenance of circadian rhythmicity (Shen et al., 1977), and both long-term potentiation and long-term depression in the hippocampus (Muller et al., 1996).

Although these expression patterns and correlations with higher-order tissue functions suggest that PSA-NCAM plays a significant role in brain physiology, there has been little study of the possible cellular mechanisms by which these effects are ob-

Received Dec. 29, 1997; revised March 2, 1998; accepted March 9, 1997.

This work was supported in part by National Institutes of Health Grants HD18369 and NS32779. T.S. was supported in part by the Yamada Science Foundation. We thank Lynn Landmesser, Karl Herrup, and Alfred Malouf for critical reviews of this manuscript.

Correspondence should be addressed to Dr. Urs Rutishauser, Department of Genetics, Case Western Reserve University, 2109 Adelbert Road, Cleveland, OH 44106.

Copyright (ㄷ) 1998 Society for Neuroscience $\quad 0270-6474 / 98 / 183757-10 \$ 05.00 / 0$ tained. With the developmental processes of axon innervation and neural precursor migration, the details of altered cell position and morphology, as well as the nature of the interactions being affected by PSA, have been investigated (Landmesser et al., 1990; Ono et al., 1994; Tang et al., 1994; Daston et al., 1996). In contrast, the characterization of the architectural basis for the adult CNS defects has been limited to a brief description of a delamination of the pyramidal cell layer in the hippocampus of NCAM mutant mice (Tomasiewics et al., 1994).

Two more detailed studies of hippocampal structure in PSAdeficient mice have been undertaken: a recent analysis of the mossy fiber layer by conventional Timm's and Golgi's stainings in adult NCAM-null mutants (Cremer et al., 1997), and the present study using DiI tracing and synapsin I labeling of mossy fibers together with an enzymatic and mutational perturbation of PSANCAM. In our approach, we have been able to obtain a highresolution description of the mossy fiber projection and, in particular, of thin fibers and synaptic terminals located in the pyramidal cell layer. Moreover, by comparing the enzymatic and mutational models, it has been possible to evaluate the specific role of PSA and the effects of genetic background differences that reside in the mutant population.

\section{MATERIALS AND METHODS}

Animals and reagents. CF1 and 129/SvJ mice were obtained from Charles River Laboratories (Wilmington, MA) and Jackson ImmunoResearch (West Grove, PA), respectively. The NCAM-180-deficient mice were generated as described by Tomasiewics et al. (1994). Forty-three CF1, nine 129/Sv, and seven NCAM-180-deficient mice were used for analyzing mossy fiber distribution. Endo $\mathrm{N}$ was prepared by the method of Hallenbeck et al. (1987). Both the anti-PSA antibodies and endo $\mathrm{N}$ have been shown to have a strict specificity for PSA and do not recognize or affect any other sialic acid-containing structures in the embryo (Hallenbeck et al., 1987; Sato et al., 1995). The mouse monoclonal antibody $(\mathrm{mAb})$ 12E3 (IgM) against PSA was prepared as described by Seki and 
Arai (1991a). Mouse IgG monoclonal anti-synapsin I was obtained from Calbiochem (San Diego, CA). Peroxidase-conjugated goat anti-mouse $\mathrm{IgM}$, peroxidase-conjugated goat anti-mouse IgG, fluorescein-conjugated goat anti-mouse IgM, and rhodamine-conjugated goat anti-mouse $\operatorname{IgG}$ were purchased from Cappel (West Chester, PA).

Endo $N$ injection. To remove PSA from the brain with endo $\mathrm{N}, 1 \mu \mathrm{l}$ of the enzyme (at a dilution of over 1:2000) was injected into the lateral ventricle of postnatal day 1 (P1) CF1 mice with a glass micropipette, as described previously (Ono et al., 1994). The endo N diffused rapidly throughout the brain and removed all detectable PSA within $1 \mathrm{~d}$ for 3-4 weeks. For control mice, the same amount of boiled endo $\mathrm{N}$ was injected in the same manner as with nonboiled endo $\mathrm{N}$ mice. The mossy fiber distribution was analyzed $15 \mathrm{~d}$ and 1.5 months after the injection. Each experimental group consisted of 9-12 animals.

Immunohistochemistry. Animals were deeply anesthetized with sodium pentobarbital and perfused intracardially first with PBS followed by $4 \%$

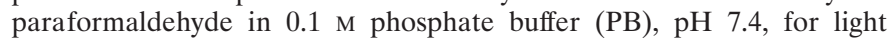
microscopic studies, or by $4 \%$ paraformaldehyde and $0.1 \%$ glutaraldehyde in PB for electron microscopic studies. The brains were removed from the skull and post-fixed overnight in $4 \%$ paraformaldehyde in $\mathrm{PB}$ at $4^{\circ} \mathrm{C}$. The cerebral cortices containing the hippocampal formation were dissected away from the remaining brain structure, and 1- to 2-mm-thick slices were cut in a plane transverse to the septotemporal axis of the hippocampal formation at the approximate midpoint of the axis. For cryostat sections, the slices were kept in $20 \%$ sucrose in PBS at $4^{\circ} \mathrm{C}$ overnight, embedded in OTC compound, and then cut by a cryostat into $10 \mu \mathrm{m}$ sections. For light microscopy of vibratome sections and electron microscopy, the slices were cut by a vibratome into $50 \mu \mathrm{m}$ thickness.

Cryostat or vibratome sections were washed with PBS and pretreated with $100 \%$ methanol containing $0.3 \% \mathrm{H}_{2} \mathrm{O}_{2}$ for $30 \mathrm{~min}$, followed by washing with PBS. The sections were first reacted with mouse IgM mAb $12 \mathrm{E} 3(1: 5000)$ or mouse monoclonal IgG anti-synapsin I $(1: 50)$ at $4^{\circ} \mathrm{C}$ for 24 or $48 \mathrm{hr}$, and after washing with PBS the sections were incubated at room temperature for 1-2 hr with goat anti-mouse IgM conjugated with peroxidase $(1: 100)$ or goat anti-rabbit $\mathrm{IgG}$ conjugated with peroxidase (1:100). Next, the sections were washed with PBS and incubated in $0.02 \%$ 3,3'-diaminobenzidine tetrahydrochloride (DAB) and $0.005 \% \mathrm{H}_{2} \mathrm{O}_{2}$ in $0.05 \mathrm{M}$ Tris buffer, $\mathrm{pH} 7.6$, for $5-10 \mathrm{~min}$. In vibratome sections, the sections were preincubated with DAB for $30 \mathrm{~min}$, and then $0.005 \% \mathrm{H}_{2} \mathrm{O}_{2}$ was added. The sections were counterstained with methyl green.

Immunoelectron microscopy. The vibratome sections were incubated in $0.1 \mathrm{M} \mathrm{NaIO}_{4}(10 \mathrm{~min})$ and then in $\mathrm{NaBH}_{4}(15 \mathrm{~min})$, followed by immersion in $5 \%$ dimethylsulfoxide $(30 \mathrm{~min})$ at room temperature. Next, the sections were incubated with mouse IgM mAb 12E3 (1:5000) for 24-48 hr at $4^{\circ} \mathrm{C}$ and then with anti-mouse IgM conjugated with peroxidase (1:100) for $3 \mathrm{hr}$ at room temperature. The sections were incubated with DAB solution for $30 \mathrm{~min}$ and then incubated with a DAB solution containing $0.005 \% \mathrm{H}_{2} \mathrm{O}_{2}$ for $5-10 \mathrm{~min}$. Each of the above steps was followed by washing with PBS. Finally, the sections were post-fixed with $1 \% \mathrm{OsO}_{4}$ in $\mathrm{PB}$, dehydrated, and embedded in Epon 812. Ultra-thin sections were mounted on uncoated grids, stained with lead citrate, and examined using a JOEL $1200 \mathrm{CX}$ microscope.

DiI labeling and photoconversion. Mice were perfused with $4 \%$ paraformaldehyde in PB under deep sodium pentobarbital anesthesia and immersed for $2-6 \mathrm{hr}$ in the same fixative at $4^{\circ} \mathrm{C}$. The cerebral cortices containing the hippocampal formation were dissected away from the remaining brain structure. Then, $\sim 1$-mm-thick slices were cut in a plane transverse to the septotemporal axis of the hippocampal formation at the approximate midpoint of the axis, and the block of the medial part of the dentate gyrus containing crescent was cut away. A $1 \%$ DiI solution (Molecular Probes, Junction City, OR) in dimethylformamide was then placed on the cut surface of the dentate gyrus (the hilus region). Specimens were stored in the same fixative at $37^{\circ} \mathrm{C}$ for 1 week. For photoconversion, the DiI-labeled vibratome sections were put in DAB solution, and the specimens were illuminated for $1-2 \mathrm{hr}$ with a Nikon microscope using a $10 \times$ objective, an HBO mercury lamp, and a rhodamine excitation filter (Bartheld et al., 1990). The DAB solution was replaced every $30 \mathrm{~min}$. The sections were mounted on slide glass and counterstained with methyl green.

Quantitative analyses. Synapsin I-positive boutons in the CA3a were counted in every second section, and an average of eight sections per mouse were analyzed. Each group consisted of 9-12 mice. The statistical significance of the results was assessed by using Student's $t$ test. Although the terms CA3a-c are primarily based on the terminology of Ishizuka et al. (1990), for convenience in quantitation of synapses we defined these subdivisions as follows. First, a straight horizontal line was drawn along the lower margin of the pyramidal cell layer that corresponds to the infrapyramidal mossy fiber band. Second, the proximal edge of the horizontal line was determined by a vertical line that makes contact with the proximal edge of the CA3 pyramidal cell layer, and the distal edge was determined by a vertical line that makes contact with the outer margin of the pyramidal cell curve. Third, two vertical lines were made to divide the horizontal line (between the proximal and distal edges) into three equal parts and in this study are referred to as CA3c, CA3b, and CA3a, respectively.

\section{RESULTS}

\section{PSA expression in the CA3 pyramidal cell layer}

In previous studies, PSA-NCAM expression was found throughout the entire dentate gyrus of early postnatal rats, followed by a persistence of expression in the mossy fiber layer and a decrease in staining in other regions (Seki and Arai, 1991b). As shown in Figure $1 A$, strong PSA expression is seen in the large suprapyramidal and infrapyramidal mossy fiber bundles, as well as in intrapyramidal mossy fibers that leave the infrapyramidal mossy fiber bundle and run across the pyramidal cell layer to join the suprapyramidal mossy fiber bundle. In addition to these thick fiber bundles, PSA-positive mossy fibers penetrate into the CA3 pyramidal cell layer and often display a dotted pattern of PSA expression. Immunoelectron microscopic observation revealed many PSA-positive fine fibers among pyramidal cells (Fig. 1B), whereas the pyramidal cells and typical mature mossy fiber synaptic boutons were devoid of PSA (Fig. 1C). The PSA-positive fibers contained many vesicles and at various points made synapse-like junctions with pyramidal cell bodies. These junction sites were also PSA-negative (Fig. 1B).

\section{Development of mossy fibers in normal and endo $\mathrm{N}$-treated mice}

In the normal mouse and rat, innervation of the pyramidal cell layer by mossy fibers begins in the early postnatal period and reaches its mature configuration at P12-P15. Initially only suprapyramidal mossy fibers are observed, but by P6-P9 as the bundle of the suprapyramidal mossy fibers becomes thicker, large infrapyramidal mossy fiber bundles are formed, and a few fine collateral sprouts penetrate into the pyramidal cell layer (Amaral, 1979; Amaral and Dent, 1981; Gaarskjaer, 1985) (our unpublished observations).

To evaluate the role of PSA in this process, endo $\mathrm{N}$ was injected into the lateral ventricle of $\mathrm{P} 1$ mice, resulting in rapid diff usion of the enzyme throughout the brain, and the mossy fibers and terminal boutons were examined in P15 and 1.5-month-old mice. This study was greatly aided by use of a combination of DiI labeling and photoconversion techniques that enabled visualization of mossy fibers and their terminal boutons. To establish the efficacy of endo $\mathrm{N}$ over this period, PSA immunoreactivity was monitored at P15, 1 month, and 1.5 months after the injection. No PSA was detected at P15, there was weak staining on some granule cells and mossy fibers by P30, and by 1.5 months nearly normal levels of PSA expression had returned.

In mice treated with endo $\mathrm{N}$, we did not observe a change in the overall pattern or extent of the suprapyramidal bundle (Fig. $2 A, B)$. The most obvious effect of PSA removal concerned the thin processes in the CA3 pyramidal cell layer region (Fig. $1 A$ ), and an analysis of this perturbation was performed at P15 (Fig. 2).

In control mice, the suprapyramidal and infrapyramidal mossy fibers were formed as large compact bundles (Fig. 2A,C,E). The suprapyramidal bundles were observed above the CA3 pyramidal cells (stratum lucidum) and gave rise to a few individual processes 

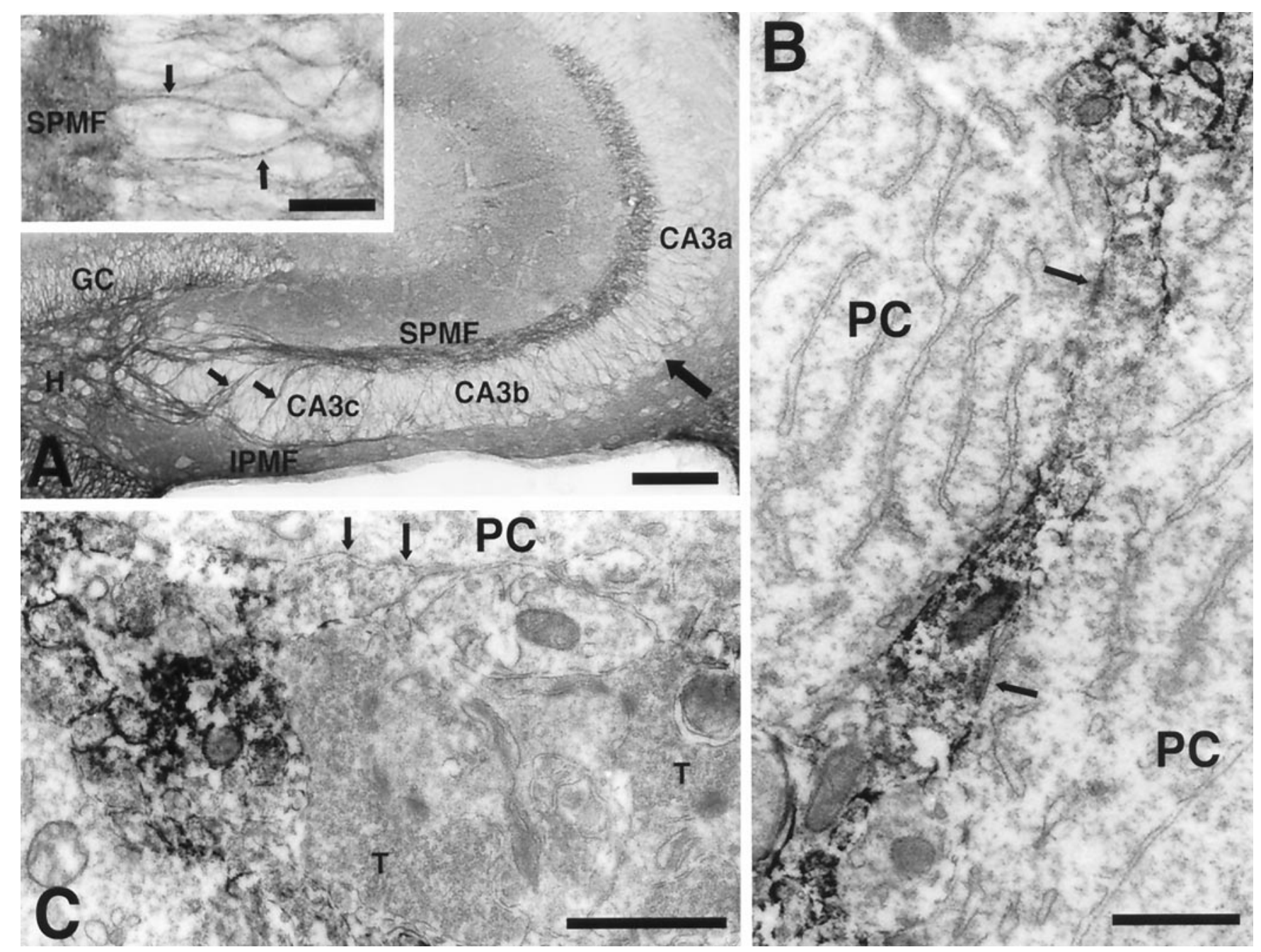

Figure 1. PSA expression in the hippocampal formation of a 15-d-old CF1 mouse. A, Strong PSA expression is seen in the large suprapyramidal (SPMF) and infrapyramidal (IPMF) mossy fiber bundles, as well as in intrapyramidal mossy fibers that leave IPMF, run across the pyramidal cell layer, and join the SPMF (small arrows). In addition to these thick fiber bundles, fine PSA-positive fibers are found in the pyramidal cell layer (large arrow). At high magnification (inset) these small fibers often displayed a dotted pattern of PSA expression (arrow). GC, Granule cell layer; $H$, hilus. Scale bar, $100 \mu$ m; inset, $25 \mu \mathrm{m} . B$, Immunoelectron micrograph of PSA on a vesicle containing mossy fiber in the CA3a pyramidal cell layer. The dotted staining pattern in the inset of $A$ is apparent as a patchy distribution of PSA staining in which cell adherence junctions (arrows) with pyramidal cell (PC) bodies are located in the PSA-negative regions. Scale bar, $1 \mu \mathrm{m}$. $C$, Immunoelectron micrograph showing a typical mature mossy fiber terminal $(T)$ with many vesicles and several synapse-like junctions (arrows). Unlike the neighboring darkly immunostained axonal process, this terminal is PSA-negative. Scale bar, $1 \mu \mathrm{m}$.

penetrating the middle (CA3b) and distal (CA3a) parts of the pyramidal cell layer (Fig. $2 E, G$ ). Only a few of these fine fibers contained mossy fiber boutons. The infrapyramidal mossy fibers ran below the pyramidal cell layer and then usually curved dorsally at the point of the proximal and middle CA3 pyramidal cell layer to join the suprapyramidal mossy fibers (Fig. 2A,C).

In endo $\mathrm{N}$-treated mice, the suprapyramidal mossy fiber bundles were similar in appearance to those of control mice. However, there were many more fine processes emanating from this bundle and penetrating along erratic paths into the middle and distal CA3 pyramidal cell layer (Fig. $2 F, H$ ). Some of these processes possessed a number of typical mossy fiber boutons. Similarly, infrapyramidal mossy fibers were formed below the CA3 pyramidal cell layer, but the bundle was less compact, with many fine fibers following separate paths through the CA3 pyramidal cell layer (Fig. 2D). This behavior was clearest in the middle part of the CA3 pyramidal cell layer in which the fibers continued to wander within the pyramidal cell layer and displayed numerous mossy fiber boutons (Fig. 2F). The morphological difference between the infrapyramidal mossy fibers of control and endo N-treated mice was also clear in electron micrographs (Fig. $3)$. In control mice, the unmyelinated mossy fiber axons were tightly fasciculated into large bundles. In contrast, in endo $\mathrm{N}$-treated animals the fascicles were much smaller and disorganized, with many other elements such as basal dendrites and terminal boutons penetrating into the bundles.

\section{Mossy fiber synaptic boutons}

Because mossy fiber boutons were a consistent feature of the aberrant fibers in the endo N-treated mice, synapsin I immunohistochemistry was used to identify mossy fiber terminals more directly. In normal P15 animals, the synapsin I-positive mossy fiber terminals were visualized as dark spots in a compact band corresponding to the location of the large suprapyramidal and infrapyramidal mossy fiber bundles (Fig. 4A,C). Few boutons were detected within the pyramidal cell layer in the CA3b and 

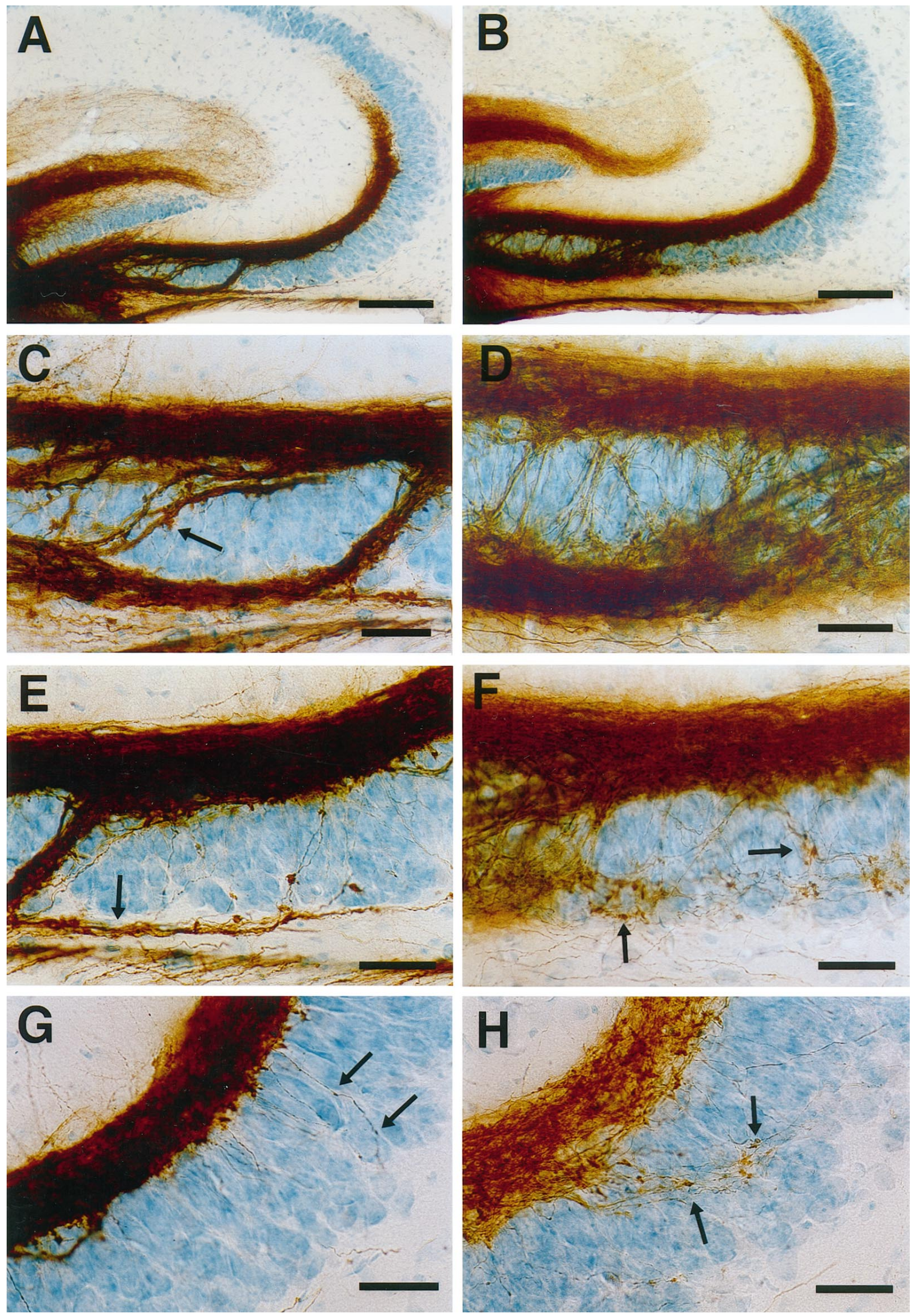

Figure 2. Mossy fiber distribution in 15-d-old control $(A, C, E, G)$ and endo N-injected $(B, D, F, H) \mathrm{CF} 1$ mice. The mossy fibers were labeled with DiI with photoconversion to a DAB reaction product (see Materials and Methods). $A, B$, Low-magnification micrograph showing that the large suprapyramidal mossy fiber bundles are similar images in control $(A)$ and endo $\mathrm{N}$-treated mice $(B) . C, D$, Higher-magnification image of the CA3c subfield. In control mice $(C)$, the intrapyramidal (small arrow) and infrapyramidal (large arrow) mossy fibers are compactly bundled. In endo N-treated mice $(D)$, these bundles are more loosely arranged. $E, F$, Higher-magnification image of the CA3b subfield. In control mice $(E)$, the infrapyramidal mossy fibers (Figure legend continues) 

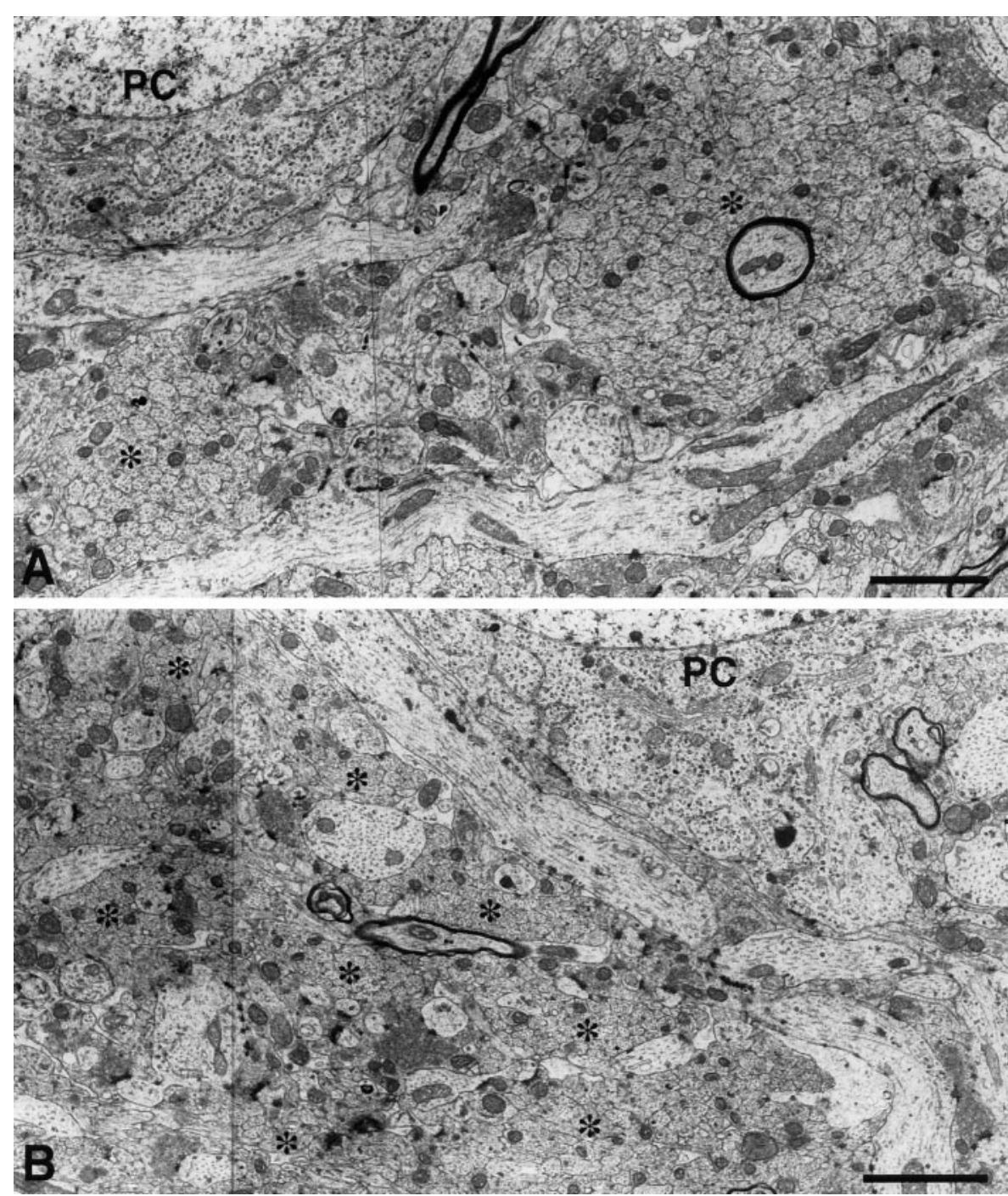

Figure 3. Electron micrograph of infrapyramidal mossy fibers in the CA3c subfield of 15 -d-old control $(A)$ and endo $\mathrm{N}$-injected $(B) \mathrm{CF} 1$ mice. Sections were cut perpendicular to the mossy fibers. In control mice, unmyelinated mossy fiber axons were tightly fasciculated in large bundles (asterisks), whereas in endo $\mathrm{N}$-treated mice, the fascicles were much smaller and disorganized, with many other elements such as basal dendrites and terminal boutons penetrating into the bundles. Scale bar, $2 \mu \mathrm{m}$.
CA3a subfields. In endo N-treated mice, the density of synapsin I-positive boutons in the suprapyramidal mossy fiber bundles was not significantly changed, although numerous boutons were found scattered within the pyramidal cell layer in CA3c and CA3b (Fig. $4 B, D)$. These results could be readily quantitated, and at P15 the number of synapsin I-positive terminals was approximately seven times greater in the CA3a pyramidal layer of the PSA-negative mice than in control mice (Fig. 4E).

\section{Mossy fiber patterns in young adult mice}

An important aspect of the effects of endo N-induced removal of PSA is that they persist in the adult hippocampus. As noted above, by 1.5 months after the enzyme treatment at P1, PSA resumed its normal level and pattern of expression. Nevertheless, the invasion of the infrapyramidal layer with fine mossy fibers persists with irregularly oriented intrapyramidal fine mossy fibers forming a web between the suprapyramidal and infrapyramidal mossy fiber bundles (Fig. 5). These aberrant fibers could well have physiological consequences, because the number of synapsin I-positive terminals in this region remains five times greater than in controls (Fig. 4E).

\section{Development of mossy fibers in NCAM-180-deficient mice}

As noted in previous studies on cell migration (Ono et al., 1994), it is valuable to compare results obtained with endo $\mathrm{N}$ with those produced by mutation of the NCAM gene. The advantage of endo $\mathrm{N}$ is that it can be introduced at a particular stage (P1 in this study) and in principle only affects PSA, whereas with mutation (in this study, the creation of a mouse that does not produce the $180 \mathrm{kDa}$ isoform of NCAM that at these developmental stages carries nearly all of CNS-associated PSA) it is effective throughout life and does not risk injection artifacts or possible contaminants.

(arrow) run as a fascicle below the pyramidal cell layer. In endo N-treated mice $(F)$, the infrapyramidal mossy fibers are unfasciculated and wander through the pyramidal cell layer, often forming synapse-like structures on the pyramidal cells (arrows). $G, H$, Higher-magnification image of the CA3a subfield. In control mice $(G)$, fibers arising from the suprapyramidal mossy fibers penetrate into the pyramidal cell layer and display small varicosities. In endo N-treated mice $(H)$, such fibers are more numerous and possess a number of clearly defined synaptic terminals. Scale bars: $A, B, 100 \mu$ m; $C-H$, $25 \mu \mathrm{m}$. 

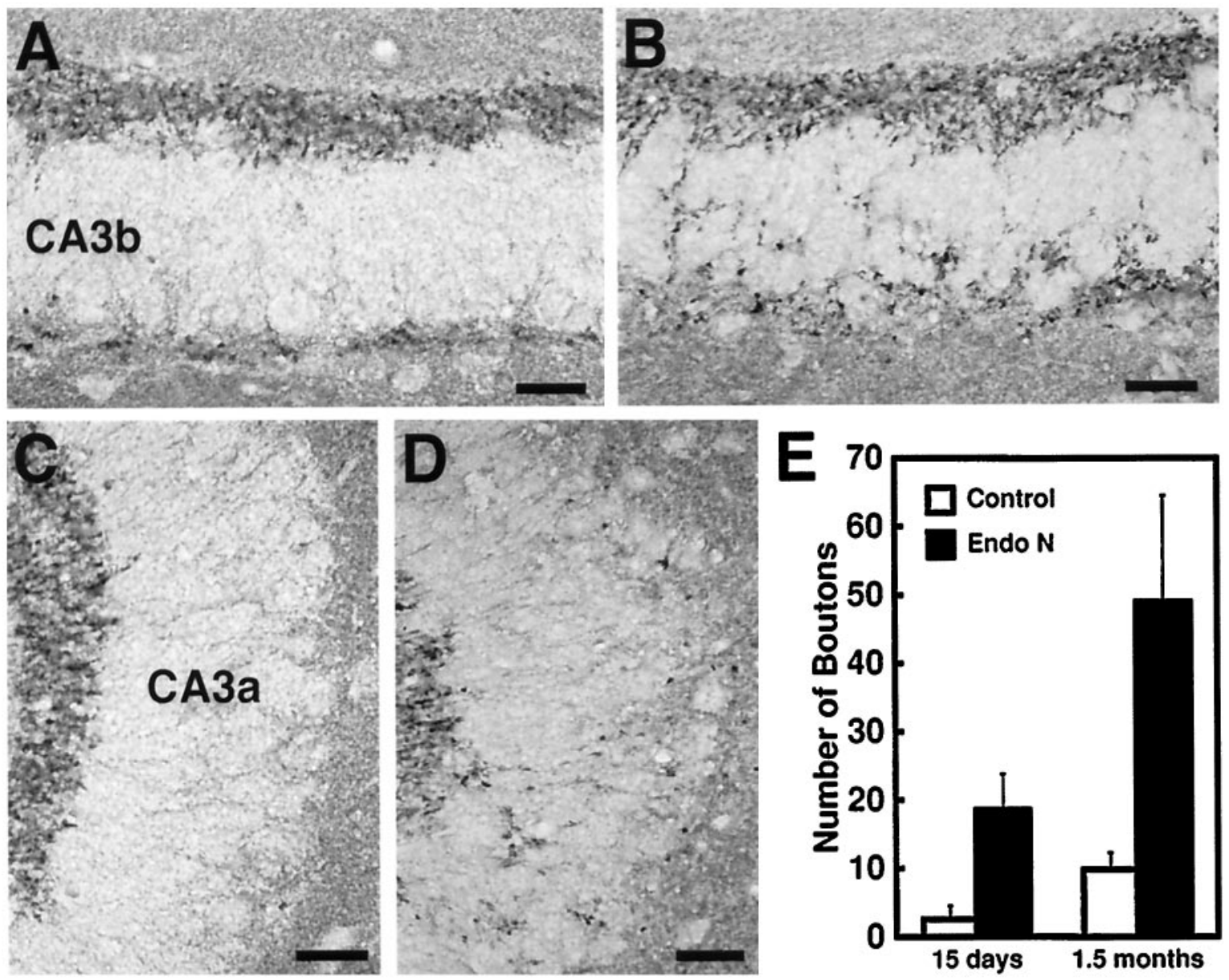

Figure 4. Mossy fiber terminal bouton distribution in the subfields CA3b $(A, B)$ and CA3a $(C, D)$ of 15-d-old control $(A, C)$ and endo N-injected $(B$, $D$ ) CF1 mice as revealed by synapsin I immunohistochemistry. A quantitation of mossy fiber bouton density in the subfield CA3a of control and endo $\mathrm{N}$-injected mice is shown in $E$. In control animals, a large number of mossy fiber boutons are seen in the suprapyramidal and infrapyramidal mossy fiber band, and only a few are distributed within the pyramidal cell layer. Significant differences were observed between control and endo N-treated mice at both P15 and 1.5 months. In endo N-treated mice, a larger number of boutons are seen scattered within the pyramidal cell layer. Error bars indicate SD; $p<0.0001$. Scale bar, $25 \mu \mathrm{m}$.
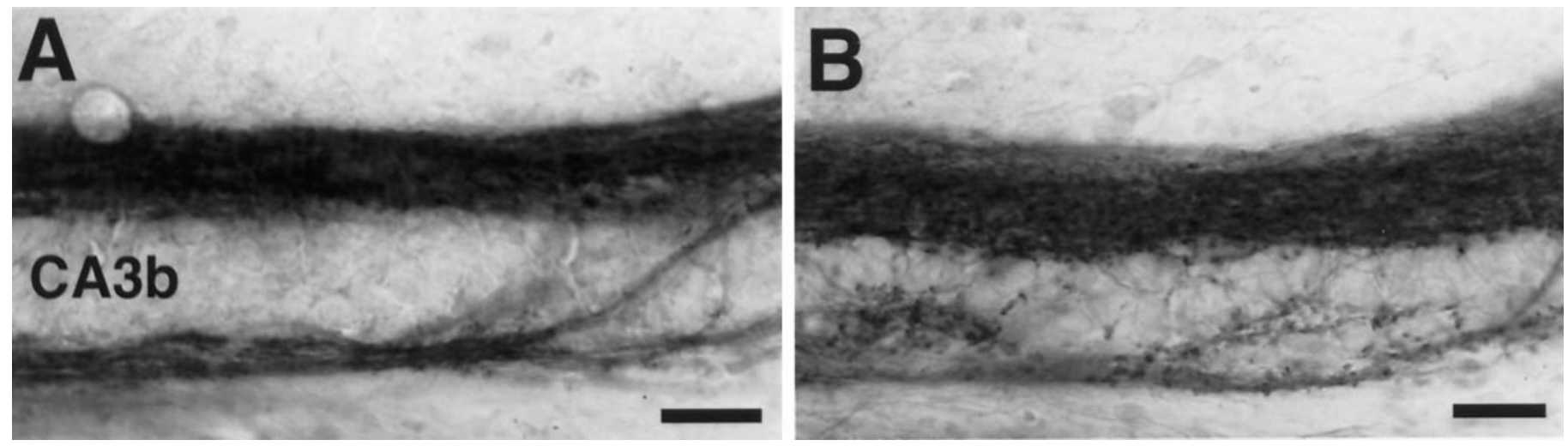

Figure 5. Mossy fiber distribution in the CA3b subfield of 1.5-month-old control and endo N-injected $(B)$ CF1 mice. The mossy fibers were labeled with DiI with photoconversion to a DAB reaction product. In controls $(A)$, the suprapyramidal, infrapyramidal, and intrapyramidal mossy fibers are compactly bundled. In endo N-treated animals $(B)$, the ectopic fibers seen at P15 persists with randomly oriented fine mossy fibers distributed within the pyramidal cell layer and bearing typical mossy fiber terminals. Scale bar, $25 \mu \mathrm{m}$.

Before analyzing mossy fiber distribution in the NCAM-180deficient mice, it was established that in neonatal brain only very low levels of PSA (possibly associated with other NCAM isoforms) were found on the mutant mossy fibers. Another impor- tant consideration is the genetic backgrounds of the controls and mutants. In the present experiments, mossy fiber distributions were compared among wild-type CF1, wild-type $129 / \mathrm{SvJ}$, and the NCAM-180-deficient mutation on a background containing genes 
from both the CF1 and 129 strains. This combination presents a potential problem, because different mouse strains can have significantly different patterns of mossy fiber innervation (Barber et al., 1974; Schwegler and Lipp, 1983), and in particular the 129 strain has a large bifurcation of the mossy fiber bundles in CA3c and sometimes CA3b that is not present in CF1 (Fig. 6, compare $A, C, E$ for 129 ; Fig. 2, compare $A, C, E$ for CF1) or C57BL (Schwegler and Lipp, 1983). However, it may be noted that Cremer et al. (1997) did not detect a difference in mossy fiber distribution for 129 and C57BL mice as viewed by Timm's staining.

Nevertheless, these strain differences between 129 and CF1 mice never included the type of defasciculated and ectopic fibers seen in the distal half (CA3a region) of the pyramidal cell layer of the endo $\mathrm{N}$-treated mice. In fact, the mutant mice used in this study have an overall bundle pattern most similar to that of the wild-type 129 strain, with a splitting of the mossy fiber layer in CA3c and CA3b (Fig. 6A,C,E, $G$ ), plus a large number of defasciculated intrapyramidal mossy fiber in CA3a. That is, in the mutant many fine mossy fibers were found to run between suprapyramidal and intrapyramidal mossy fiber bundles, forming a web between them, and many of these fibers displayed large varicosities characteristic of mossy fiber boutons (Fig. 6D,F,H). Despite this similarity between the enzyme and mutation-induced perturbations, it should be noted that the mutant phenotype appears to be more extreme because there is a continued growth of defasciculated intrapyramidal fibers into CA3a (Fig. 6B, H). However, as with the endo $\mathrm{N}$ treatment, we did not observe a change in the NCAM-mutant mice in the overall pattern or extent of the suprapyramidal bundle (Fig. 6A,B).

\section{DISCUSSION}

The major finding of this study is that both the genetic deletion of PSA-NCAM and the enzymatic removal of PSA at P1 from growing mossy fibers in the hippocampus result in a partial misrouting of these axons into the pyramidal cell layer. Associated with this change in pattern is a defasciculation of mossy fiber bundles, wandering of these small fibers along haphazard paths, and the frequent appearance of mossy fiber terminals. These fibers and terminals persist in the mature brain, even after the reappearance of PSA in the enzyme-treated animals.

This discussion will begin with a comparison of the present study with the recent report by Cremer et al. (1997). The focus of the earlier study, which primarily used relatively low-resolution methods such as Timm's, neurofilament, or tau staining, was on the extent of outgrowth and reduction in bundle size of mossy fiber axons as detected in the adult. Our analysis of the developing hippocampus used the high-resolution DiI tracing methods and the specificity of synapsin I staining to examine the behavior of both thick and fine fibers, as well as synaptic terminals, in the mossy fiber and pyramidal cell layers.

The two studies have yielded similar results with respect to the divergence of relatively large bundles in the CA3a region of NCAM-mutant mice. In contrast, in CA3c and CA3b we did not observe such splitting after endo $\mathrm{N}$ treatment, and in our analysis at least, the branching observed in this region reflected the 129 strain genetic background rather than the NCAM mutation (Barber et al., 1974; Schwegler and Lipp, 1983). However, it is also possible that this discrepancy between the two studies reflects differences between the null NCAM mutation and our more restricted removal of PSA or the NCAM-180 isoform.

More importantly, the additional information we have obtained for fine ectopic fibers and their associated terminals is valuable in considering the mechanisms by which PSA-related defects are generated. In particular, we were struck by the persistent invasion of the pyramidal cell layer by unfasciculated mossy fiber processes and the formation of many synapses by these fibers within that layer. These observations lead us to suggest two cellular mechanisms by which removal of PSA could have produced the observed effects: (1) an increase in the number of unfasciculated mossy fibers or collaterals that can grow into the pyramidal cell layer, and (2) an inhibition of the withdrawal of a normally transient innervation of this region. There is evidence in the literature supporting each mechanism, and it is possible that both are relevant.

At first consideration, an increase in the number of unfasciculated fibers is not an effect that would be expected from loss of PSA. That is, at the membrane-molecular level, removal of PSA appears to enhance cell interactions (Rutishauser, 1992), which in vivo can lead to an increase in axon-axon fasciculation (Landmesser et al., 1990; Tang et al., 1994). However, in other contexts, such as the innervation of the tectum by optic fiber extensions (Yin et al., 1995) and the outgrowth of spinal cord motor axons in culture (Rutishauser et al., 1988; Acheson et al., 1991), it has been proposed that PSA removal preferentially enhances grow th cone environment interactions, thus resulting in the type of defasciculation and ectopic innervation observed here for mossy fibers. Alternatively, it has been suggested that PSA might contribute positively to fiber fasciculation, and thus its absence would result in smaller bundles (Cremer et al., 1997).

The second mechanism, an inhibition of fiber withdrawal by the absence of PSA, fits well with both the effects of PSA on cell membrane interactions and the fact that in normal hippocampal development there is a transient innervation of the pyramidal cell layer by mossy fiber extensions (Amaral, 1979; Amaral and Dent, 1981). These earlier studies described Golgi-impregnated extensions arising from mossy fiber expansions that are similar in morphology to the DiI-labeled fiber collaterals that we found penetrating into the pyramidal cell layer. The extensions grew to their maximal length at approxiamtely P14 and then retracted by P28, suggesting that they are transient structures associated with hyperinnervation. Furthermore, at the ultrastructural level the extensions were found to contain many vesicles and to have made synaptic junctions with pyramidal cells with a morphology distinct from that of typical mossy fiber terminals and similar to those described here for PSA-positive fibers located in the pyramidal cell layer. Together, these studies suggest that the PSA-positive fibers in the pyramidal cell layer are transient mossy fiber collaterals or extensions, form transient synapse-like junctions with pyramidal cells, and are subsequently withdrawn. Thus the level of such fibers in the pyramidal cell layer is likely to represent a steady-state level with active extension and retraction, and if PSA removal either inhibits the retraction or stabilizes the extension, then the pattern of ectopic innervation would be both augmented and persistent.

With respect to stabilization, it is notable that the punctate staining of PSA on mossy fibers was observed to be negatively correlated with junction formation in that both adherens and synaptic junctions were found to be free of PSA. This raises the interesting issue of whether PSA removal promotes junctional contacts that stabilize the ectopic processes or whether the persistence of the fibers leads to more junction formation. In the case of synapses, the fact that the number of terminals increased from day 15 to 1.5 months in both the endo N-treated and control animals would seem to argue that persistence by itself is a factor. 

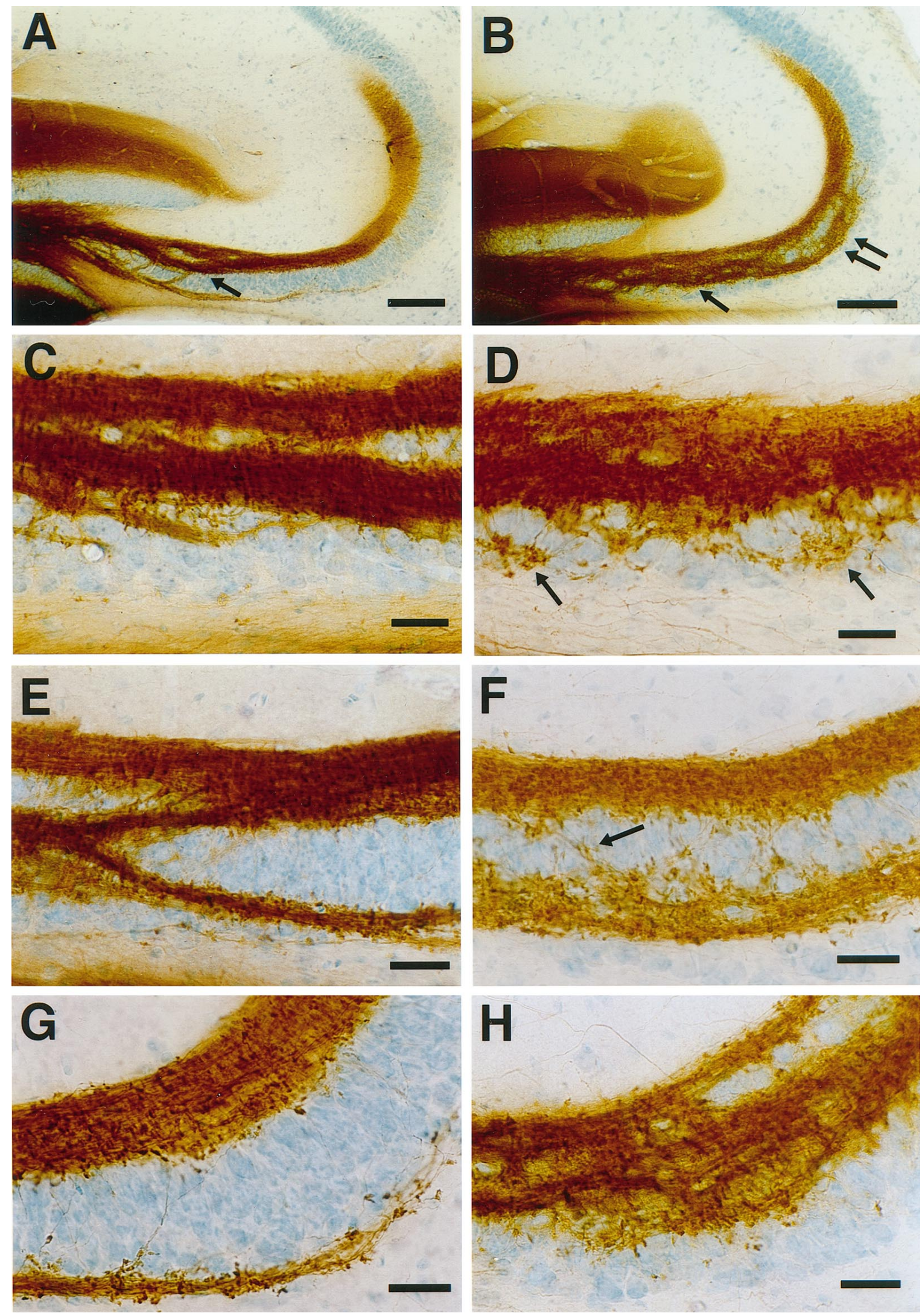

Figure 6. Mossy fiber distribution in 1-month-old 129/SvJ wild-type $(A, C, E, G)$ and NCAM-180-deficient $(B, D, F, H)$ mice. The mossy fibers were labeled with DiI and the fluorescence photoconverted to a DAB reaction product. $A, B$, Low-magnification micrograph showing that large mossy fiber bundles invade the CA3c pyramidal cell layer in both 129 wild-type and NCAM-mutant mice. However, only in the mutant do these fibers extend into the CA3a subfield (double arrow). $C, D$, Higher-magnification image of the CA3c subfield. In the mutant, a larger number of fine mossy fibers arise from the intrapyramidal bundle. These ectopic fibers are distributed randomly throughout the lower part of the pyramidal cell layer and make mossy fiber synaptic (Figure legend continues) 
Nevertheless, the large mossy fiber terminals seen in the PSAnegative animals at early stages (P15) are already distinguishable from the relatively small varicosities found in normal animals and would be consistent with an active role for PSA in suppressing junction formation in the pyramidal cell layer.

In sum, the role of PSA in morphological development of hippocampal mossy fibers appears to be the regulation of an exuberant and transient outgrowth of collaterals and the formation of synapses by those axons. Given these findings, the role of PSA during normal development of axon pathways remains to be considered more broadly. PSA is abundantly expressed on essentially all growing fiber tracts in the developing CNS, and thus the effects seen here are likely to be relevant to other situations. With respect to the transient projection of excessive numbers of or ectopically placed PSA-positive fibers into their target tissue, it should be noted that such behavior is quite widespread, including for example the transient contact of climbing fibers with the soma of Purkinje cells in the cerebellum (Mason and Gregory, 1984; Altman and Bayer, 1997), exuberant outgrowth of intracortical axons followed by a selective pruning of early formed branches (Gomez-DiCesare et al., 1997), and the polyinnervation of muscles by motor neurons in the peripheral nervous system (Colman et al., 1997). If the present findings are relevant, then one would predict that PSA removal might produce a persistence of such immature fiber patterns with possible physiological consequences arising from the presence of inappropriate terminals. In fact, our previous studies on the effects of endo $\mathrm{N}$ on tectal innervation by optic fibers (Yin et al., 1995) may also require additional interpretation in that the apparent defasciculation of nerve bundles in the tract and rostral tectum could have been augmented by a persistence of normally transient axonal explorations in this region.

Finally, whether the behavioral defects observed in NCAM- or PSA-deficient mice (Cremer et al., 1994; Becker et al., 1996) might reflect in part the effects seen here in hippocampus remains to be addressed. Several potentially valid points can be raised. First, increases in the innervation of the pyramidal cell layer have been correlated with a defect in avoidance learning (Lipp et al., 1983). Second, in the mature hippocampus there are many more synapses in the CA3 pyramidal cell layer of mutant or endo N-treated animals so that a morphological correlate of physiological function is at least present in the adult. Third, innervation of CA3 by PSA-positive mossy fibers continues through much of adulthood, presumably leading to new connections (Seki and Arai, 1993b, 1995), and it is reasonable to expect that loss of this PSA would produce defects related to those found in development. It should also be noted that in epileptic animals, there is an aberrant growth of mossy fibers in the pyramidal cell layer that is similar in appearance to the ectopic fibers observed in the endo N-treated or NCAM mutant animals (Ben-Ari and Represa, 1990; Parent et al., 1997). Obviously this extrapolation from development to physiology, not to mention the undefined role of the hippocampus itself in such behaviors, represents an extended speculation. In any case, the present study provides both new information of the cellular basis of PSA function and the first pieces of information related to the long path between the genetic mutation of the NCAM gene and its associated behavioral phenotypes.

\section{REFERENCES}

Acheson A, Sunshine JL, Rutishauser U (1991) NCAM polysialic acid can regulate both cell-cell and cell-substrate interactions. J Cell Biol 114:143-153.

Altman J, Bayer AS (1997) Development of the cerebellar system. Boca Raton: CRC.

Amaral DG (1979) Synaptic extensions from the mossy fibers of the fascia dentata. Anat Embryol (Berl) 155:241-251.

Amaral DG, Dent JA (1981) Development of the mossy fibers of the dentate gyrus. I. A light and electron microscopic study of the mossy fibers and their expansions. J Comp Neurol 195:51-86.

Barber RP, Vaughn JE, Wimer RE, Wimer CC (1974) Geneticallyassociated variations in the distribution of dentate granule cell synapses upon the pyramidal cell dendrites in mouse hippocampus. J Comp Neurol 156:417-434.

Bartheld CS, Cunningham DE, Rubel E (1990) Neuronal tracing with DiI: decalcification, cryosectioning, and photoconversion for light and electron microscopic analysis. J Histochem Cytochem 38:725-733.

Becker CG, Artola A, Gerardy-Schahn R, Becker T, Welzl H, Schachner M (1996) The polysialic acid modification of the neural cell adhesion molecule is involved in spatial learning and hippocampal long-term potentiation. J Neurosci Res 45:143-152.

Ben-Ari Y, Represa A (1990) Brief seizure episodes induce long-term potentiation and mossy fiber sprouting in the hippocampus. Trends Neurosci 13:312-318.

Bofanti L, Olive S, Poulain DA, Theodosis DT (1992) Mapping of the distribution of polysialylated neural cell adhesion molecule throughout the central nervous system of the adult rat: an immunohistochemical study. Neuroscience 49:419-436.

Colman H, Nabekura J, Lichtman JW (1997) Alterations in synaptic strength preceding axon withdrawal. Science 275:356-361.

Cremer H, Lange R, Christoph A, Plomann M, Vopper G, Roes J, Brown R, Baldwin S, Kraemer P, Scheff S, Dagmar B, Rajewsky K, Will W (1994) Inactivation of the N-CAM gene in mice results in size reduction of the olfactory bulb and deficits in spatial learning. Nature 367:455-459.

Cremer H, Chazal G, Goridis C, Represa A (1997) NCAM is essential for axonal growth and fasciculation in the hippocampus. Mol Cell Neurosci 8:323-335.

Daston MM, Bastmeyer M, Rutishauser U, O'Leary DM (1996) Spatially restricted increase in polysialic acid enhances corticospinal axon branching related to target recognition and innervation. J Neurosci 16:5488-5497.

Gaarskjaer FB (1985) The development of the dentate area and the hippocampal mossy fiber projection of the rat. J Comp Neurol 241:154-170.

Gomez-DiCesare CM, Smith K, Rice FL, Swann JW (1997) Axonal remodeling during postnatal maturation of CA3 hippocampal pyramidal neurons. J Comp Neurol 384:165-180.

Hallenbeck PC, Vimr ER, Yu F, Bassler B, Troy FA (1987) Purification and properties of a bacteriophage-induced endo- $\mathrm{N}$-acetylneuraminidase specific for poly- $\alpha-2,8$-sialosyl carbohydrate units. J Biol Chem 262:3553-3561.

Ishizuka N, Weber J, Amaral D (1990) Organization of intrahippocampal projections originating from CA3 pyramidal cells in the rat. J Comp Neurol 195:580-623.

Landmesser L, Dahm L, Tang J, Rutishauser U (1990) Polysialic acid as a regulator of intramuscular nerve branching during embryonic development. Neuron 4:655-667.

Lipp HP, Schwegler H, Driscoll P (1983) Postnatal modification of hippocampal circuitry alters avoidance learning in adult rats. Science $225: 80-82$.

\section{$\longleftarrow$}

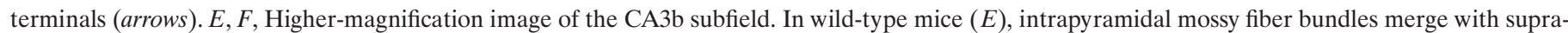

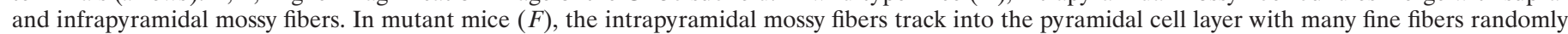

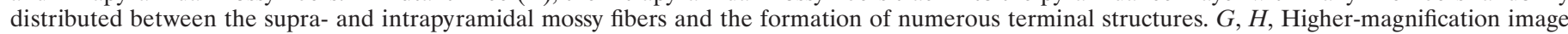

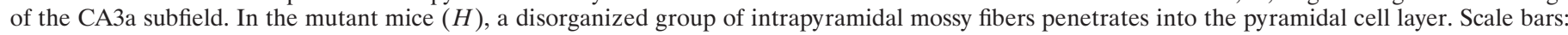
$A, B, 100 \mu \mathrm{m} ; C-H, 25 \mu \mathrm{m}$. 
Mason CA, Gregory E (1984) Postnatal maturation of cerebellar mossy and climbing fibers: transient expression of dual features on single axons. J Neurosci 4:1715-1735.

Muller D, Wang C, Skibo G, Toni N, Cremer H, Calaora V, Rougon G, Kiss JZ (1996) PSA-NCAM is required for activity-induced synaptic plasticity. Neuron 17:413-422.

Ono K, Tomasiewicz H, Magnuson T, Rutishauser U (1994) NCAM mutation inhibits tangential neuronal migration and is phenocopied by enzymatic removal of polysialic acid. Neuron 13:595-609.

Parent JM, Yu TW, Leibowitz RT, Geschwind DH, Sloviter RS, Lowenstein DH (1997) Dentate granule cell neurogenesis is increased by seizures and contributes to aberrant network reorganization in the adult rat hippocampus. J Neurosci 17:3727-3738.

Rutishauser U (1992) NCAM and its polysialic acid moiety: a mechanism for pull/push regulation of cell interactions during development? Development [Suppl 1992]:99-104.

Rutishauser U, Landmesser L (1996) Polysialic acid in the vertebrate nervous system: a promoter of plasticity in cell-cell interactions. Trends Neurosci 19:422-427.

Rutishauser U, Acheson A, Hall AK, Mann DM, Sunshine J (1988) The neural cell adhesion molecule (NCAM) as a regulator of cell-cell interactions. Science 240:53-57.

Sato C, Kitajima K, Inoue S, Seki T, Troy FA, Inoue Y (1995) Characterization of the antigenic specificity of four different anti-(alpha 2-8linked polysialic acid) antibodies using lipid-conjugated oligo/polysialic acids. J Biol Chem 270:18923-18928.

Schwegler H, Lipp HP (1983) Hereditary covariations of neuronal circuitry and behavior: correlations between the proportions of hippocampal synaptic fields in the regio inferior and two-way avoidance in mice and rats. Behav Brain Res 7:1-38.

Seki T, Arai Y (1991a) Expression of highly polysialylated NCAM in the neocortex and piriform cortex of the developing and the adult rat. Anat Embryol (Berl) 184:395-401.

Seki T, Arai Y (1991b) The persistent expression of a highly polysialylated NCAM in the dentate gyrus of the adult rat. Neurosci Res 12:503-513.

Seki T, Arai Y (1993a) Distribution and possible roles of the highly polysialylated neural cell adhesion molecule (NCAM-H) in the developing and adult central nervous system. Neurosci Res 17:265-290.

Seki T, Arai Y (1993b) Highly polysialylated neural cell adhesion molecule (NCAM-H) is expressed by newly generated granule cells in the dentate gyrus of the adult rat. J Neurosci 13:2351-2358.

Seki T, Arai Y (1995) Age-related production of new granule cells in the adult dentate gyrus. NeuroReport 6:2479-2482.

Shen H, Watanabe M, Tomasiewicz H, Rutishauser U, Magnuson T, Glass JD (1977) Role of neural cell adhesion molecule and polysialic acid in mouse circadian clock function. J Neurosci 17:5221-5229.

Tang J, Rutishauser U, Landmesser L (1994) Polysialic acid regulates growth cone behavior during sorting of motor axons in the plexus region. Neuron 13:405-414.

Theodosis DT, Rougon G, Poulain DA (1991) Retention of embryonic features by an adult neuronal system capable of plasticity: polysialylated neural cell adhesion molecule in the hypothalamo-neurohypophysical system. Proc Natl Acad Sci USA 88:5494-5498.

Tomasiewics H, Ono K, Yee D, Thompson C, Goridis C, Rutishauser U, Magnuson T (1994) Genetic deletion of a neural cell adhesion molecule variant (N-CAM-180) produces distinct defects in the central nervous system. Neuron 11:1163-1174.

Yin X, Watanabe M, Rutishauser U (1995) Effect of polysialic acid on the behavior of retinal ganglion cell axons during growth into the optic tract and tectum. Development 121:3439-3446. 